Int. J. Speleol. 15 (1986), pp. 57-71

\title{
EVIDENCE FOR KARSTIC MECHANISMS INVOLVED IN THE EVOLUTION OF MOROCCAN HAMADAS
}

\author{
Vittorio Castellani *, Walter Dragoni * *
}

\begin{abstract}
Underground tubular karst features, observed in an arid envinroment of southern Morocco, are described. On the basis of various evidences, it is suggested that such features were originated mainly by condensation water. A computation of the time necessary for their formation supports this hypothesis.
\end{abstract}

\section{RIASSUNTO}

Si descrivono delle forme carsiche ipogee tubolari osservate nel Marocco meridionale e, in base a vatie evidenze, si avanza l'ipotesi che il loro sviluppo sia dovuto essenzialmente ad acqua di condensazione. Il calcolo sui tempi di formazione rende plausibile tale ipotesi.

\section{INTRODUCTION}

The saharian regions of northern Africa are characterized by the well known "Hamadas": limestone plateaux emerging abruptly from the desertic plains with a nearly flat sub-horizontal surface. South of the Atlas mountains, the Moroccan Sahara presents many structures of this kind, scattered but impressive relicts of the continuous sedimentary continental formations deposited in the area from the early Cretaceous till the end of the Tertiary era.

*Università “'La Sapienza”, Roma

${ }^{\star}$ ^S.S.I.-C.N.R. Perugia 
From East to West, the Hamada du Meski, Hamada du Guir, KemKem and Hamada du Dra form a nearly continuos belt which runs from the Algerian border to the Atlantic ocean, roughly following the line of the High Atlas and Antiatlas ranges, some $200 \mathrm{~km}$ to the South (fig. 1). The tableland of the Hamada du Guir lays between the rivers Ziz and Guir, East of the last inhabited area of Erfoud. The upper part of this hamada is made up of a lacustrine limestone with horizontal bedding of un-

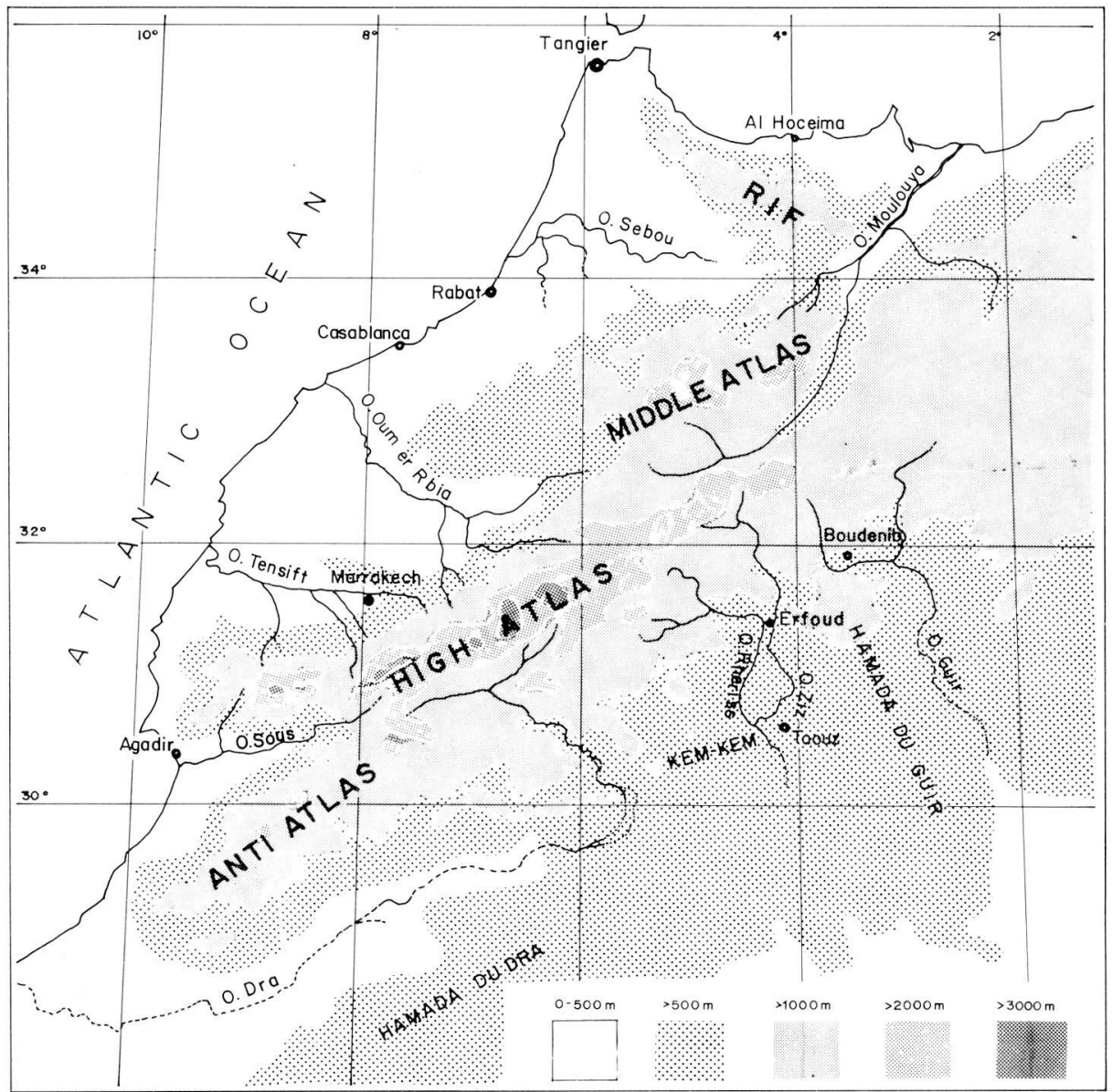

Fig. 1 Hamada du Guir, Kem-Kem and Hamada du Dra form a belt following the pattern of the High Atlas and Anti-Atlas mountains from the algerian border to the atlantic cost. 
certain recent age (Pliocene, lower Pleistocene). The edges are deep and often vertical, so that the "kreb" (the arab name for a hamada edge) looks like a natural section of the tableland. From aerial photos one can easily detect a network of drainage channels, which often abort (fig. 2) in one of the thousands of shallow depression ("dayas") which cover the hamada surface, and whose diameters range from about $1 \mathrm{~m}$ to $1-2 \mathrm{~km}$ with a maximun depth of 3-4 m.

Gautier (1951) first suggested that northern saharian dayas may originate from karstic phenomena, reporting evidences of a water absorption

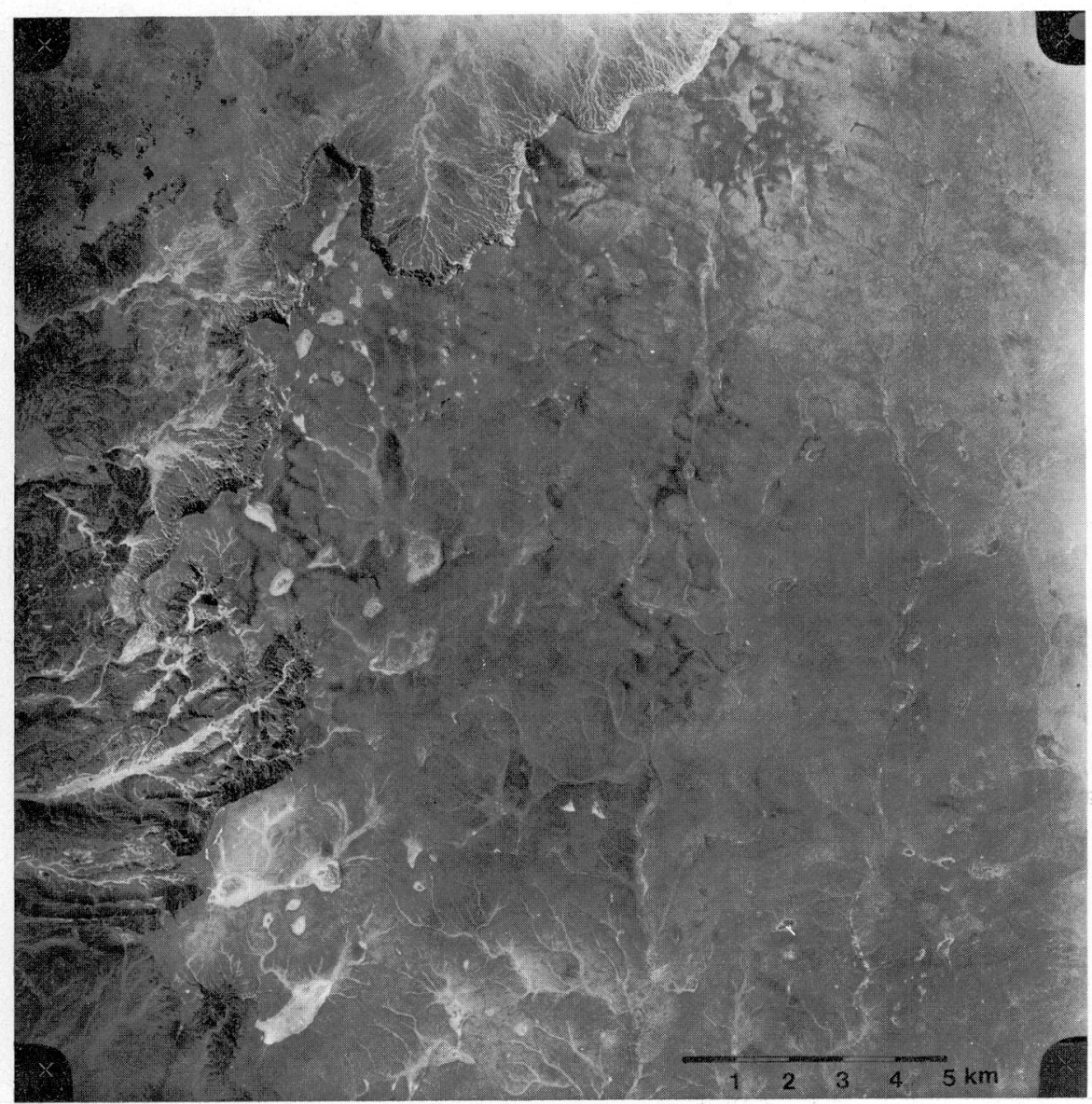

Fig. 2 An aerial photo of a portion of the Hamada du Guir, showing the sinuous border of the hamada and drainage channels, which often abort in closed "dayas". North at top. Scales in km. 


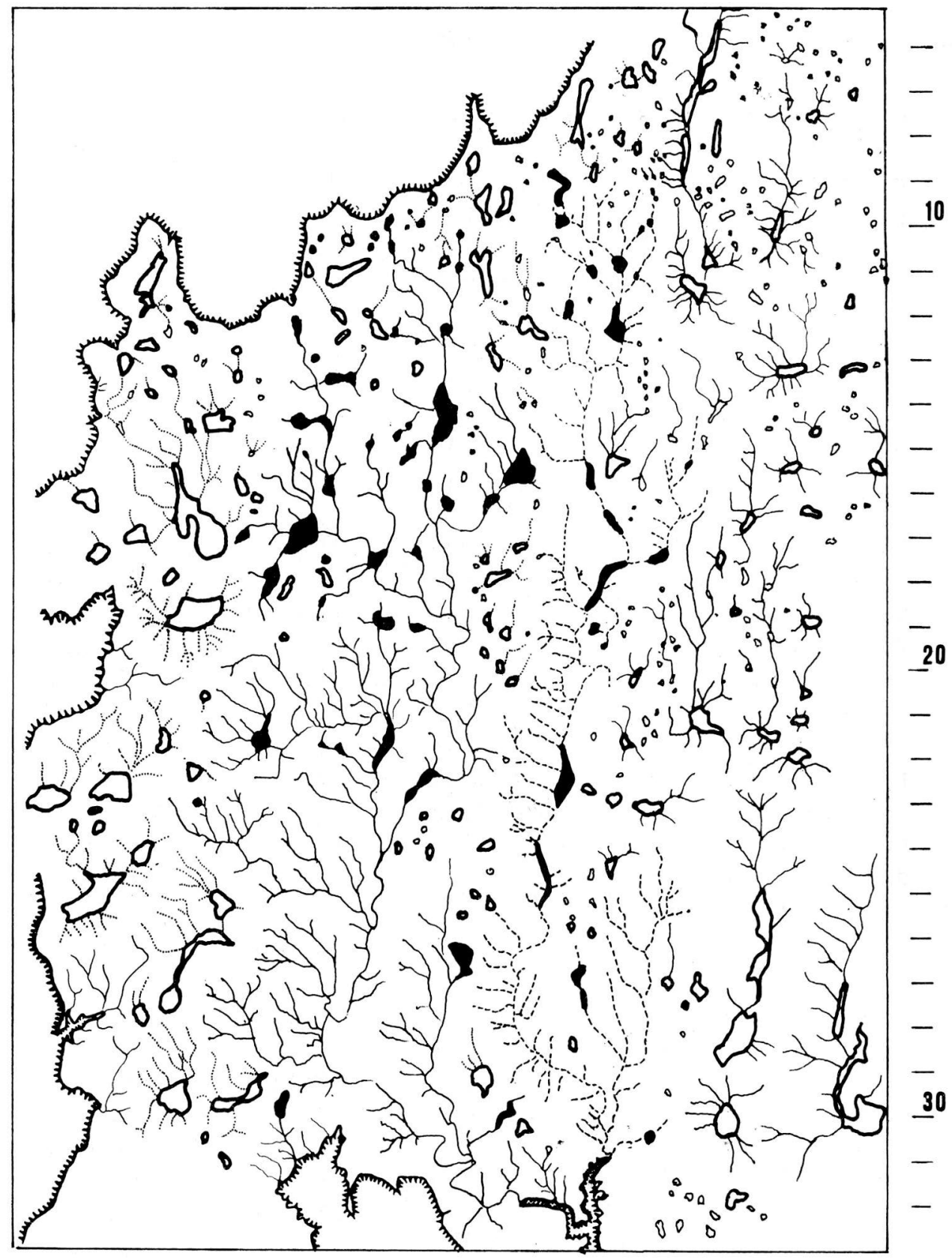

$\begin{array}{lllllllllllllllll}\mid & \mid & \mid & \mid & \mid & \mid & \mid & \left.\right|_{10} & \mid & \mid & \mid & \mid & \mid & \mid & \mid & \mid & \mid\end{array}$

Fig. 3 A map of a portion of the Hamada du Guir corresponding to the aerial photo in fig. 2. The network of drainage channels is shown, connecting (black areas) or aborting in (white areas) soil covered depression. 
up to $85 \%$ of the water collected during a heavy rainfall. This view was further strengtned by Mitchell (1970) on the basis of analogies with dolines or poljes, and later by Mitchell and Willimot (1974) who pointed out that a downward leaching of the daya floor is demonstrated by the lower salt and carbonate concentration with respect to the surrondings.

In fig. 3, derived from aerial photos, a large portion of the hamada surface is shown, where closed areas represent the soil covered central region of dayas. Though some dayas are connected to form a surface network eventually able to drain water across and out of the plateau, most of the area is made up of closed basins where rainfall water is collected and absorbed (Castellani 1977).

The surface of the hamada has been explored by means of a computerized image scanning device at the Institute of Geology of Rome University. It was found that the area covered by daya soil is about $5 \%$ of the total surface. Such a ratio does not vary considerably along the $80 \mathrm{~km}$ of hama$\mathrm{da}$ explored in such a way, which supports the idea that dayas are a constant characteristic of the hamada texture. Further suggestions for the efficiency of an underground waterflow can be found in some "edge effects", due to the lack of vegetation in the dayas near the hamada edge. This effect could be attributed to a more efficient drainage from these dayas ( $\mathrm{Ca}$ stellani and Dragoni 1977) enhancing the soil aridity.

Such a situation suggests that also in an arid environment karst phenomena can play an important role in the evolution of a limestone hama$\mathrm{da}$. This led us to investigate the way in which karst can develop in such an environment.

\section{EVIDENCE FOR DEEP KARST}

The Hamada of Guir, presently the border between Morocco and Algeria, is subject to special restrictions which greatly hinders the possibility of field investigations. Nonetheless, during a recent stay in the region we succeded in reaching a butte, a detached part of the northern border of the hamada (fig. 4), near the small village of Alî, in the Boudenib district. The surface of the butte (about $1000 \mathrm{~m}$ above sea level) is a stony desert, with almost angular stones that show its residual origin. An ispection of this surface again revealed the occurrence of the daya phenomenon: the surface was scattered with depressions whose dimensions ranged from 1 to $5 \mathrm{~m}$ in diameter and were less than $0.5 \mathrm{~m}$ deep. The stony cover did not al- 
low us to see the underlying rocky surface, so that the occurrence of a karstic sink (or a set of absorbing fractures) could be only hypothesized at this stage.

For more insight into this problem, we decided to submit the kreb to a careful inspection: if any underground karst features had been present, they would have been intersected by the surface of the eroded and fast retreating kreb.

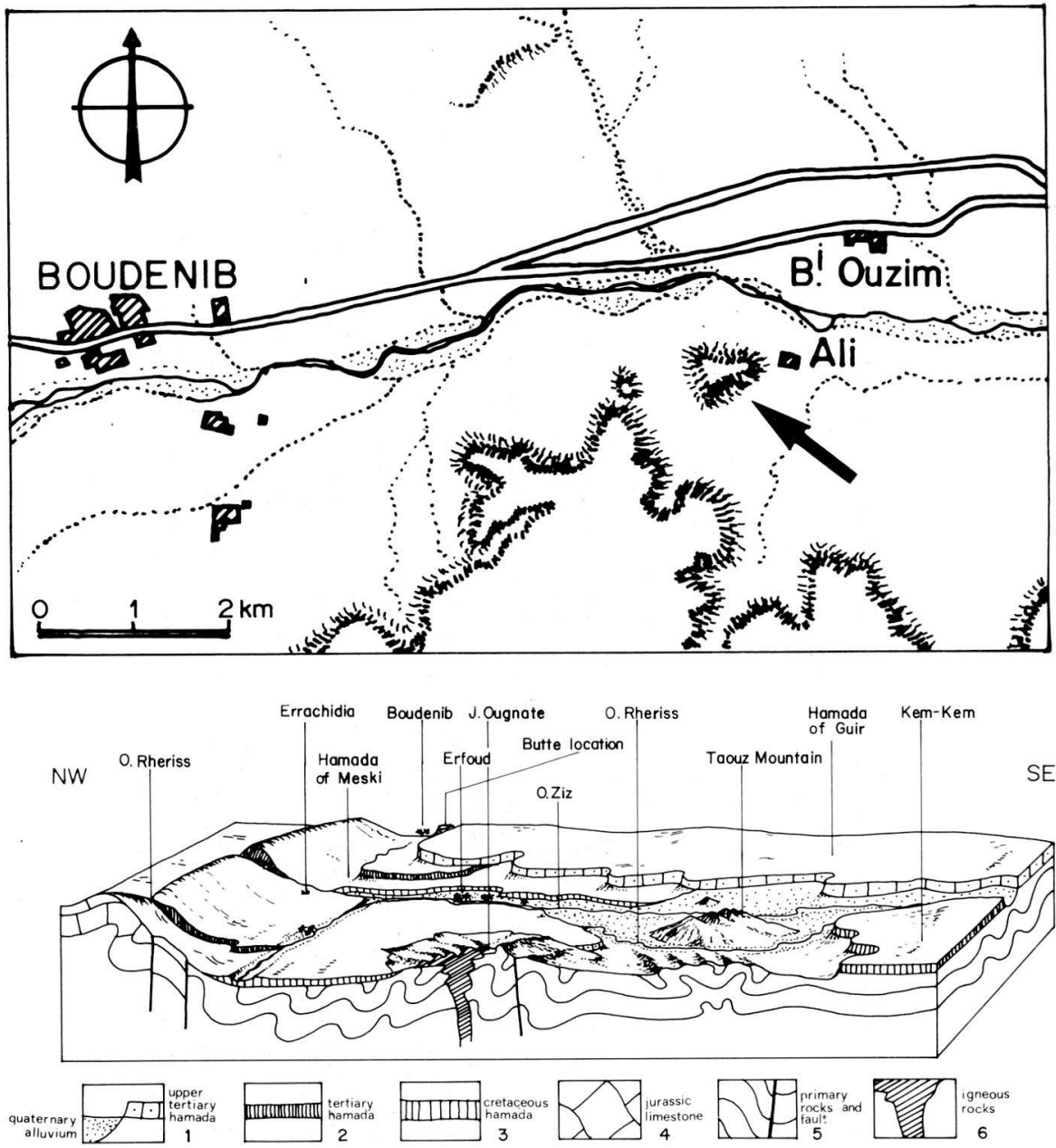

Fig. 4 a) The location of the butte near the Alì village.

b) Geological sketch of the region reffered to in the text. 
Following this inspection, we soon found clear evidence of a well developed karstic hypogeal network, able to support a consistent ground water flow. Two different and well defined morphologies could be identified. The first one involved the upper portion of the butte, had a thickness of about $15-20 \mathrm{~m}$ and was formed by vertical conducts with regular and nearly circular cross-section, whose diameters were in the range of $0.5-1.0$ $\mathrm{m}$ (fig. 5). As the kreb has been destroyed by the vertical fractures, in some areas examples could be found of cross sections of these tubes emer-

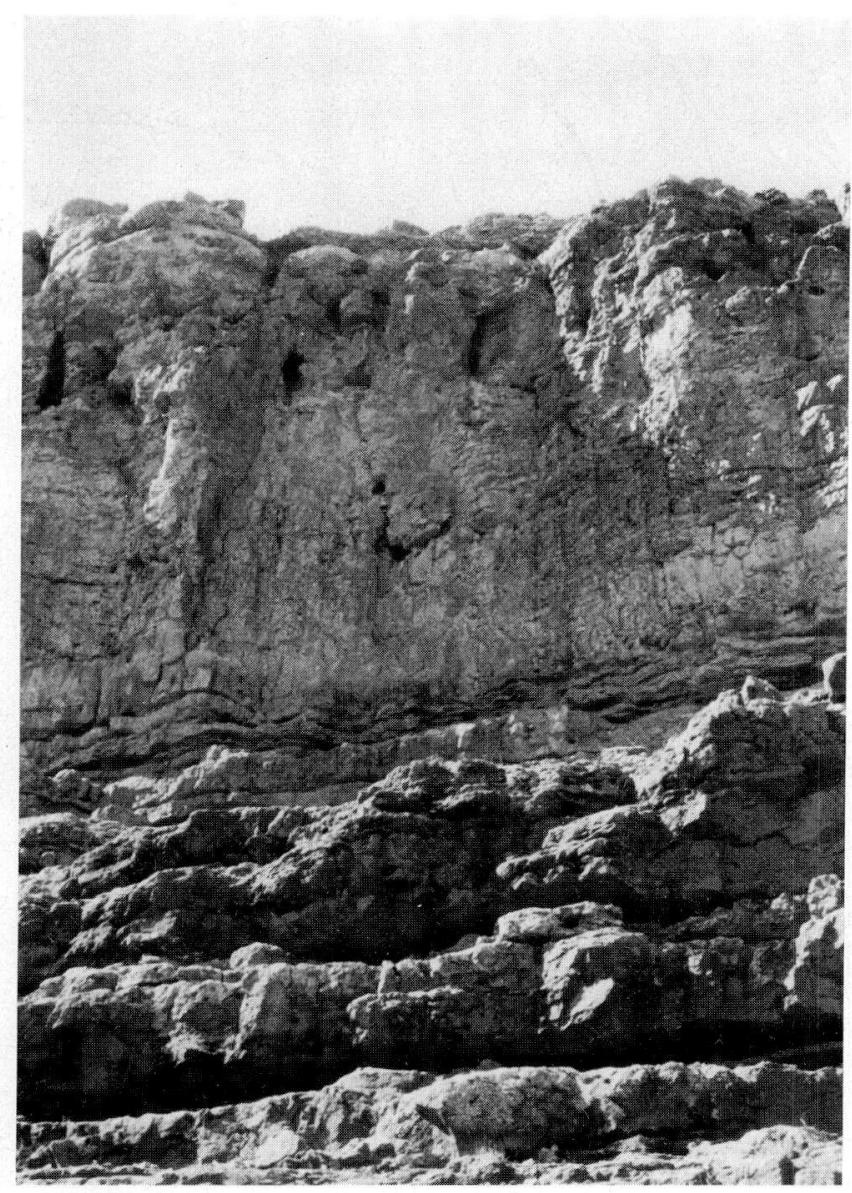

Fig. 5 The edge of the butte near Alì. One can notice that the upper portion of the limestone bank has a network of vertical tubes intersected by the edge of the butte. 

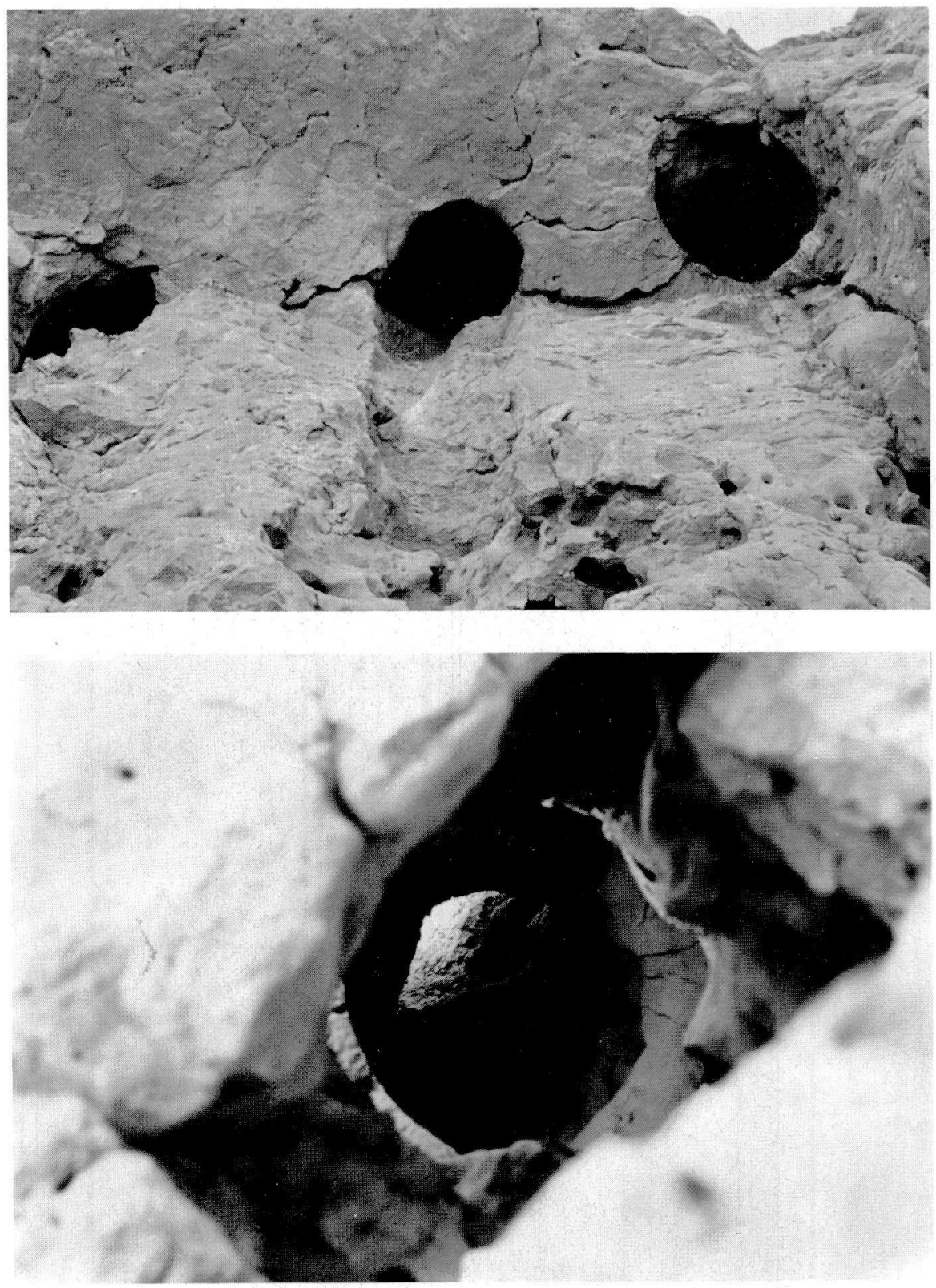

Fig. 6 a) Orthogonal view of the tubes in fig. 5

b) Another orthogonal view of the tubes in fig. 5; the ligth through the tube is due to caving in of its upper portion. 
ging on a rocky roof (fig. 6a, 6b), allowing one to view it orthogonally. In all cases, these tubes lay at the crossing of at least two families of vertical joints.

Another interesting feature was found at the contact between the limestone bank an a marl bed. For a thickness of about $1 \mathrm{~m}$ above the marl bed the limestone had strong karsification, consisting of small and tubelike cavities with a radius of up to $20-30 \mathrm{~cm}$, with a horizontal general trend (fig. 7).

These findings, as schematized in fig. 8, support the above suggestions that the daya are the surface elements of a larger karstic system. The

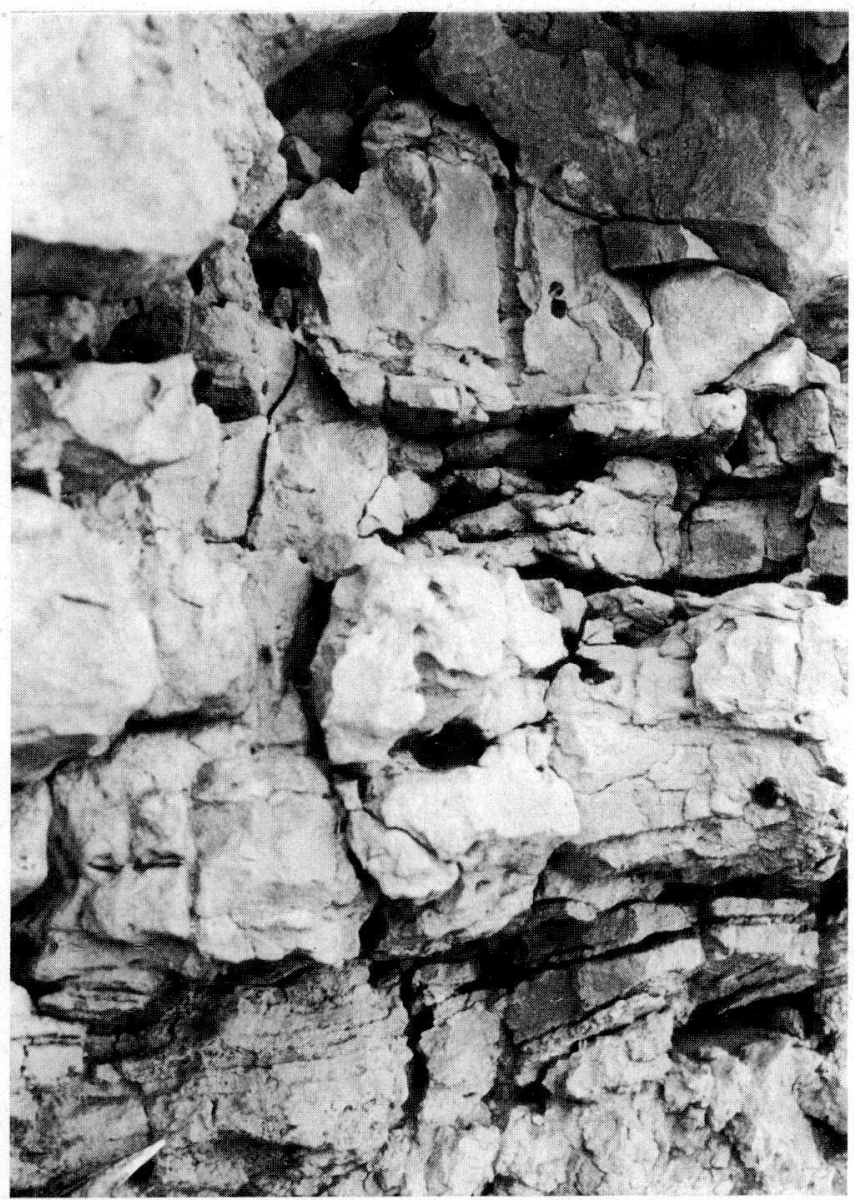

Fig. 7 Horizontal channels at the contact between the limestone and the underlying marl bed. 
occurrence of such a system and the morphology of the surface of the Hamada of Guir, can have strong implications regarding the relationship between karst and climate in general and the evolution of a calcareous plateau in arid environments in particular.

Let us refer to the two principal kinds of karst: those developing in a temperate climate and those developing in a humid tropical climate. Following the early ideas of Civijic, Grund and more recent ones [see, e.g., Smith and Atkinson (1976) and Jacus (1964)] in humid tropical areas the soil cover is extremely rich in $\mathrm{CO}_{2}$, so that "typical karstic dissolution" is much faster at soil-limestone contact than deep in the limestone mass. In such an environment Cockpit or Tower Karst develops. Obviously, this is not the case of the Hamada of Guir.

Also in a temperate humid climate (as it could be in the karst regions

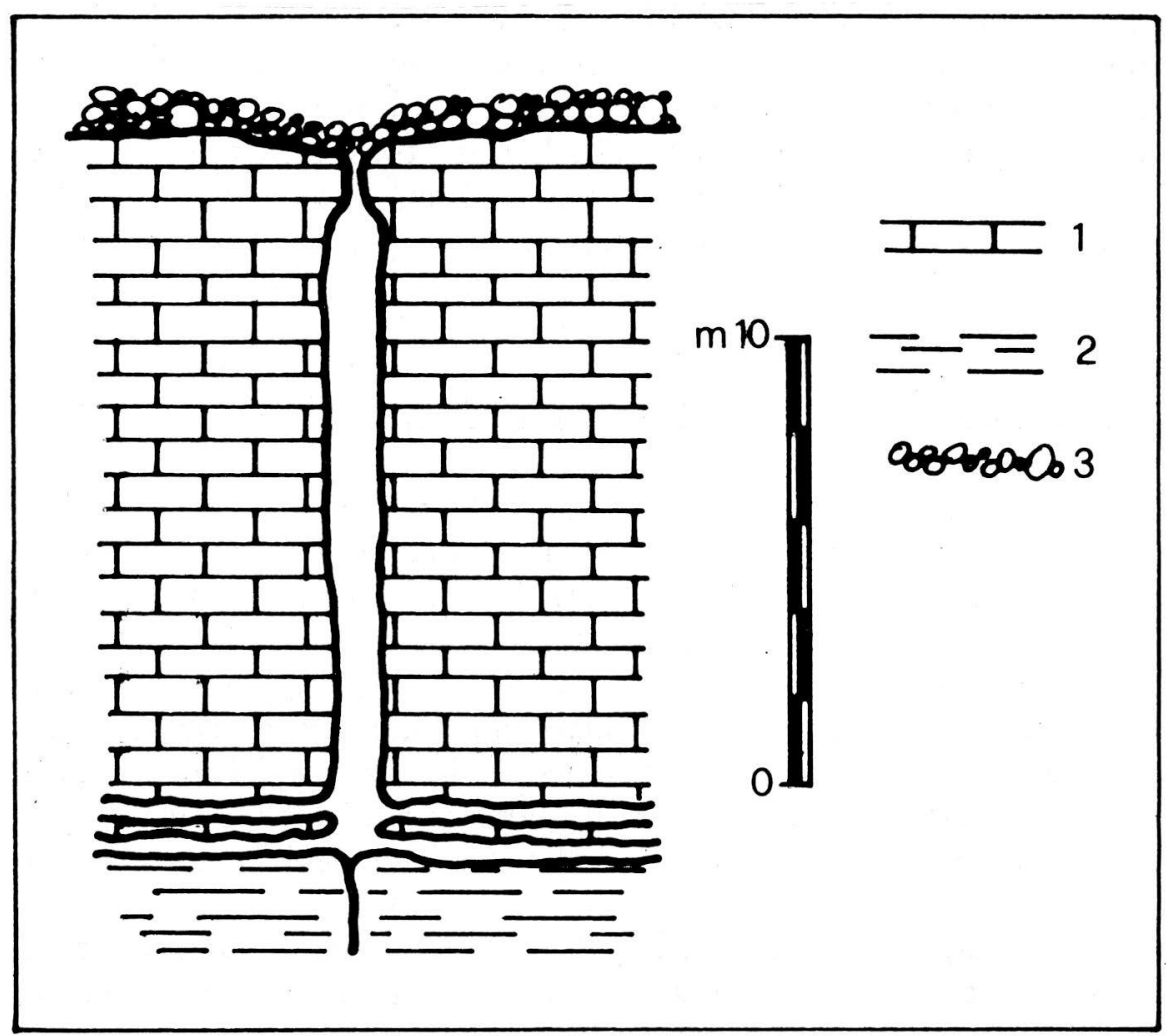

Fig. 8 A sketch of the karstic system draining the hamada: 1: limestone, 2: marl, 3: stones. 
of northern Italy and Jugoslavia), the karstic phenomena effect mainly the surface of the plateau, where, at an early stage, river channels, canyons and a complete surface drainage network are formed. Later, when the underground drainage and the surface sinks are well developed, the surface evolves towards the formation of closed basins and the water circulation is almost entirely subterraneous. However, even in such an advanced stage of evolution, the ancient surface drainage network can still be recognized. As this is not the case of the Hamada of Guir, the suggestion can be made that the system outlined in fig. 8 is independent (or almost entirely independent) of the rainfall and surface runoff.

Such hypothesis is reinforced by the evidence that in areas where rainfall, runoff and surface corrosion are the predominant karst mechanisms, the size of the surface depression is generally much larger than that of the sink holes draining the depressions. Regarding the butte near Alì the tubes sizes are about as large as the surface depressions. This suggests that the tubes formed almost independently of the weak surface erosion, and that the hypogeal karst system of the Hamada was efficient from the start, stopping the weak "surface flow" and freezing the surface evolution early on. If this be true, it would be of great importance to understand whether or not this represent a common feature of carbonatic plateaux in arid enviroments.

\section{ORIGIN AND EVOLUTION OF THE KARST}

A detailed analysis of the speleogenethic mechanisms leading to the above karstic features is out of the limits of this report. Nonetheless it is worth discussing briefly the general framework, in the hope of obtaining suggestions for more advanced investigations.

First of all, one must keep in mind the aridity of the area: at present the average rainfall is between 50 and $60 \mathrm{~mm} /$ year and the average yearly temperature is $19.6{ }^{\circ} \mathrm{C}$. The erosion of the rivers $\mathrm{Ziz}$ and Guir has detached the lacustrine sediments from the Atlas to the North, so that at present one can exclude the flow of ground water from the Atlas to the Hamada.

The main problem is posed by the tube-like vertical shafts; a mechanism based on percolating water in a vadose enviroment, in our opinion, seems unlikely. The digging would be hardly cilindrical; indeed any cilindrical shape would be quickly destroyed (percolation would most likely 
produce "channeled" surfaces, contrarily to what was observed in Alì butte tubes). One may consider the morphology as evidence, or at least as a suggestion, that the room where solution occurred was "permeated" by an aggressive agent. Following this line, one could imagine that the karst process occurred either below the water table or in an aggressive aerial ambient.

It is difficult to believe that the described morphology originated in a phreatic enviroment. The cilindrical shape of the tubes and their verticality would have required a vertical water flow, and it is hard to imagine a phreatic enviroment with such a permanent characteristic. Furthermore, the karstic tubes closely approach but never reach the hamada surface, suggesting a correlation between the present surface and karsification.

We suggest that dew condensation could have been an efficient mechanism for this purpose. It is well known that, due to the considerable temperature variations between night and day, in hot desert regions there is a large amount of water condensation on the rocky surfaces. It is also generally agreed that such water evaporates during the first hours of sunlight, causing the dissolved limestone to recrystallize.

Evidences for the efficiency of karstic erosion likely to be connected with dew can be found in the calcareous stones scattered on the desert surface. One can easily interpret the considerable erosion characterizing the bottom of such stones (fig. 9) as having been caused by dew condensed in the interspace between the stone and its desert resting place. This process progressively enlarges the interspace, leaving unaffected only the original points of contact with the surface.

We suggest that condensation of aggressive water should occur during the spring/summer at the crossing of two or more vertical fractures, if air is able to reach a depth of more than $2-3 \mathrm{~m}$, the known limit for the daily thermal wave (Schoeller 1951). Indeed, below this limit rock temperature approaches more and more the average yearly temperature, so that below that limit the rock acts as a cold point where dew must form during hot days. This would quite naturally explain the lack of efficiency just near the surface.

Available data on condensation in deserts are uncertain and do not agree. Values range between $0.4 \mathrm{~mm} /$ night and $0.1 \mathrm{~mm} /$ night (Tonini 1974). In order to obtain indications regarding the efficiency of a similar mechanism, let us assume in a deep fracture a condensation of $c=0.1$ $\mathrm{mm} /$ day and that the vertical crossing of two fractures can be assimilated to a thin vertical cylinder of radius $R$. 

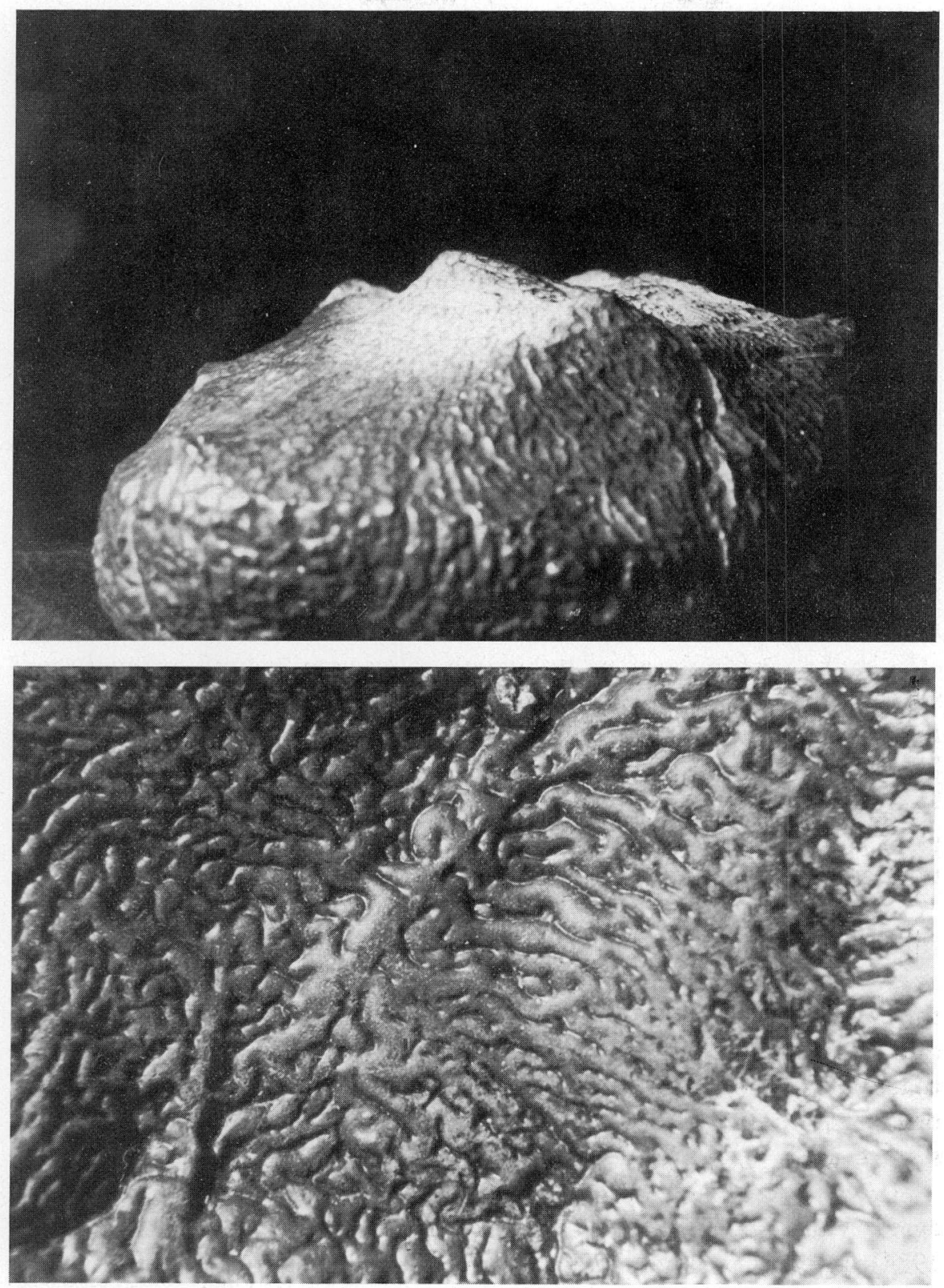

Fig. 9 a) The bottoms of limestone stones covering the surface of the hamada show evidence of a substantial erosion to be connected with limestone solubility.

b) close up of the "vermiculation" covering the surface of the stone. 
Thus, for a unit of length, the amount of condensed water is

$$
\mathrm{W}=2 \pi \mathrm{R} \times \mathrm{c},
$$

which will dissolve a volume of $\mathrm{CaCO}_{3}$ given by

$$
\mathrm{V}=\mathrm{W} \times \mathrm{S}
$$

where $\mathrm{S}$ is the solubility (by volume) of limestone in $1 \mathrm{~cm}^{3}$ of water. One has thus an increase of radius given by

$$
2 \pi \mathrm{R} \times \mathrm{dR}=\mathrm{W} \times \mathrm{S}
$$

According to Roques (1975) and Smith (1977), water in equilibrium with atmospheric $\mathrm{CO}_{2}(0.03 \%$ by volume $)$ at $10^{\circ} \mathrm{C}$ has a solubility of about $0.07 \mathrm{gr} /$ liter of $\mathrm{CaCO}_{3}$. Since the density of limestone is about 2.7 $\mathrm{gr} / \mathrm{cm}^{3}$, one can thus evaluate an increase in radius of about $2 \cdot 10^{-6}$ $\mathrm{cm} /$ day. Therefore a radius of $0.5 \mathrm{~m}$ could form in about -500.000 years. The order of magnitude of this rough calculation indicates that there it was time enough in order that dew produced karstic tubes. Note that the process would be strongly accelerated if and when circulation of air is in some way facilitates through the fracture.

\section{CONCLUSIONS}

Tube karst is a peculiar karst form that is generally neglected in the literature. It is made up of vertical and almost cylindrical cavities, often unrelated to other karst phenomena such as cave systems or dolinas. We have reported evidences that tube karst in the saharian Hamada du Guir is an important feature governing the evolution of the Hamada and suggested that it originated from water condensation.

It would be of great interest to determinate whether a similar origin can also be ascribed to tube karst found in different climates (Castellani and Dragoni 1982), where the more efficient "usual" karst mechanisms could conceal the one here hypothized.

We gratefully acknowledge prof. Marjory Sweeting for a critical lecture of an early version of the manuscript. 


\section{REFERENCES}

AtKInsons T. C., SMITH D. I. 1976: Processes, Landforms and Climate in Limestone regions, in Geomorphology and Climate, Derbyshire Ed.

CASTELLANI V. 1976: Un'analisi fenomenologica del carsismo dei daya nell'bamada du Guir, Le Grotte d'It. 6. 145-168.

CASTELLANI V., DRAGONI W. 1977: Surface karst landforms on the moroccan hamada du Guir, Proc. 7th Intern. Spel. Congr., Sheffield.

CASTELlani V., DRAGONI W. 1982: About the genesis of karstic cavities, 2. Inter. Symp. on Utilization of karstic areas, Bari.

GAUTIER M. 1951, in Action eoliennes, phenomenes d'evaporation et d'bydrologie superficielle dans les regions aride, CNRS Paris (1953).

JAKUCS L. D. 1964: Morphogenetics of karst regions, A. Hilger ed. Bristol.

MITCHELL C. W. 1970: The interpretation of dayas on aerial photographs of arid areas, III Intern. Symposium fur Photointerpret. Dresden.

Mrtchell C. W., Willimot S. G. 1974: Dayas of the Moroccan Sahara and other arid regions, Geogr. J. 140.441.

PICKNETT R. G., BRAY L. G., STEIMER R. D. 1976: The chemistry of cave waters, in The Science of Speleology, T. D. Ford and C. H. D. eds., Academic Press. London.

ROQUES H. 1972: Chimica dei carbonati ed Idrologia carsica, Le Grotte d'It. IV. 37-72.

SCHOELLER H. 1951: Condensation occultes, en particulier dans les affleurements de terrain calcaires ou greseux de l'A frique du Nord, in Action eoliennes, ..., CNRS, Paris (1953), p. 353.

SCHOELLER H. 1959: Hydrologie des regiones arides. Progres recents. Recherches sur la zone aride, XII Unesco.

TONINI D. 1974: Elementi di Idrografia ed Idrologia, Libr. Univers. Venezia. 